\title{
Management Pathway for Difficult Catheters
}

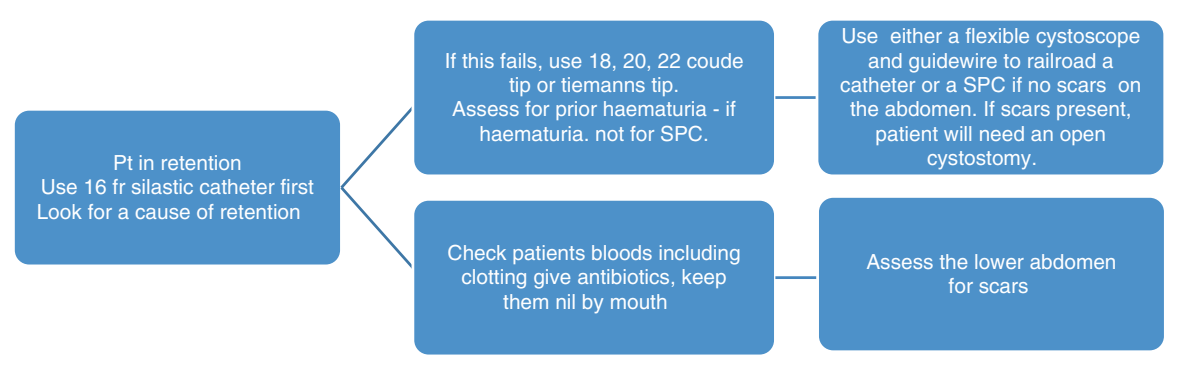

\section{Suggested Reading}

Prentiss RJ, Mullenix RB, Feeney MJ, Howe GE, Steel JF, Cole JW, Flynn VJ, Walther AB, Sorensen MB. The catheter. How to use and when not to use. Calif Med. 1969;111(4):265-71.

Tadtayev S, Mazaris E. Difficult urethral catheterisation made easy: validation and the new application of the established technique. Ann R Coll Surg Engl. 2013;95(4):300.

Wagner KR, Bird ET, Coffield KS. Urinary catheterization: a paradigm shift in difficult urinary catheterization. Curr Urol Rep. 2016;17(11):82.

Willette PA, Coffield S. Current trends in the management of difficult urinary catheterizations. West J Emerg Med. 2012;13(6):472-8. 